\title{
Risk Sermayesinin Yüksek Maliyeti ve Startuplar'ın İzlemesi Gereken Yatırım Stratejisi
}

\section{High Cost of Venture Capital and Investment Strategy Startups Should Follow}

\author{
Mustafa Şeref AKIN ${ }^{1}$ (D)
}

\section{ÖZ}

Bu çalışmada risk sermayesi yatırımcılarının beklentilerini karşılamaları için almaları gereken hisse oranlarının matematiksel açıımı gösterilmektedir. Başlangıç safhası atlatıldıktan sonra, sermaye intiyacını karşılamada girişimcinin etrafındaki tanıdıkları yetersiz kalmaktadır. Bu nedenle, startup kurucuları öz kaynaklarının bir kısmını yatırım getirisi bekleyen diğer yatırımcılara satarlar. Startuplar'ın büyümeye geçme aşamasında risk sermayedarlarının desteği bu anlamda kritiktir. Buradaki en önemli açmaz ne kadar yatırıma ne kadar hisse oranı verileceği yönündedir. Risk sermayesinin organizasyon yapısı ve startuplar'daki başarı oranının düşük olması sebebiyle, maliyeti yüksek bir sermayedir. Yatırımcıların beklenti oranları genel piyasa beklentilerinin çok üstünde değildir. Risk sermayesini pahalı yapan unsurlar 5-10 yıl arası değişen uzun bekleme dönemi ve startup'ın başarılı olma intimalinin \%10-20 arası değişmesidir. Bundan dolayı indirgeme oranları \%50'lerin çok üstüne çıkmaktadır. Genellikle startup girişimcisi çok az sermaye karşılığında çok fazla hisse vermiş gibi bir hayal kırıklığı yaşamaktadır. Bu az sermayenin arkasındakinin risk sermayesini göstererek bu oranların bir pazarlık konusu veya bir sömürüden çok sektörün kurgusunun neticesi olduğunun anlaşılmasıdır. Bu şartlarda, startup kurucularının izleyebilecekleri en doğru strateji risk sermayedarlarıyla sıkı pazarlık etmek yerine gerektiği kadar finansman sağlamalarıdır.

Anahtar kelimeler: Risk sermayesi, Startup, Nakite nakit, En düşük getiri oranı

JEL Sınıflaması: G24, M13

\section{ABSTRACT}

In this article, the mathematical expansion of the share that the venture capital investors should receive to meet their expectations is shown. After the initial phase has been overcome, the entrepreneurs' acquaintances around them are insufficient
1Prof. Dr., Erzincan Binali Yıldırım Üniversitesi, İktisadi ve İdari Bilimler Fakültesi, Erzincan, Türkiye

ORCID: M.S.A. 0000-0002-1850-9118

Corresponding author/Sorumlu yazar: Mustafa Şeref AKIN,

Erzincan Binali Yıldırım Üniversitesi, İktisadi ve İdari Bilimler Fakültesi, Erzincan, Türkiye

E-mail/E-posta: mustafa.akin@erzincan.edu.tr

Submitted/Başvuru: 21.03.2020 Accepted/Kabul: 02.05.2020

Citation/Atıf: Akin, M.Ş. (2020). High Cost of Venture Capital and Investment Strategy Startups Should Follow. Istanbul Iktisat Dergisi - Istanbul Journal of Economics, 70(1), 229-245. https://doi.org/10.26650/ISTJECON2020-0010 
in meeting the capital requirement. For this reason, founders sell some of their resources to other investors who expect a return on investment. In this sense, the support of venture capitalists is critical during the growth phase of the startup. The most crucial dilemma here is how much financing and how many shares will be given. Due to the organizational structure of venture capital and the low success rate in start-ups, it is a costly capital. Expectation rates of investors are not much above the general market ones. The factors that make venture capital so costly are the long waiting period of 5-10 years, and the chances of start-up success being between $10-20 \%$. As a result, the discount rates are well above $50 \%$. Entrepreneurs are disappointed when they give too many shares for little capital. Under these circumstances, the most accurate strategy a start-up can follow is to provide as much financing as needed rather than to negotiate tightly with venture capitalists.

Keywords: Venture capital, Startup, Cash to cash, Hurdle rate

JEL Classification: G24, M13

\section{EXTENDED ABSTRACT}

A startup starts with the opportunity of potential economic gain. It must have supportive resources (financing, management) to take advantage of the opportunity in a competitive and uncertain environment. Bank loans require regular cash flows, and therefore, startups cannot access debt financing. Banks also demand mortgages in return for credit. In the initial funding, the entrepreneur, himself, his friends and relatives play an essential role. After the initial phase, the entrepreneur's acquaintances around him are insufficient in meeting the capital requirement. For this reason, startup founders sell some of their resources to other investors who expect a return on investment. The most crucial dilemma here is in terms of how much investment will be given for how much share. Does this have a methodology? How does it handle the math? What are the strategies that startup founders should follow?

Usually, the startup entrepreneur is disappointed if he has given too many shares in exchange for very little capital. Sometimes they reject the offer. In this article, the organization and financial structures of venture capital are covered. It is shown that these calculations are the result of the sector's foundation rather than a bargaining issue or exploitation.

Due to the high uncertainty for both parties, it is difficult to determine the true value of newly established startups. Often, the younger the startup, the more 
historical data is missing, and the higher are the uncertainties that affect future performance which make it difficult to appreciate the company.

Venture capital is the capital of an entrepreneurial group from other individuals and institutions. Risk capital entrepreneurs are called limited partners, as they only provide money. Limited partners are pension funds, endowments, companies, and wealthy people.

General partners are those working in venture capital firms. They make investment decisions and use capital from limited partners or their own resources.

The contract between partners is usually for ten years. This period can be divided into three parts. The new investment is made in the first period. In the second period, there are some new investments or additional investments to the existing investments, and in the third period, exists are realized. On average, 10 to 15 investments are made. Many of them fail.

Venture capital is an expensive financial instrument. The discount rate used by risk capitalists is much higher than the standard project evaluation discount rates. In particular, the effect of this reduction rate is observed in the high shareholding demanded against investment.

There are two main factors behind the discount rate: the setup of venture capital firms and the risk of ventures. Venture capital uses other people's money for a long time. Limited partners are waiting for a return by adding to this waiting period.

The industry average is that one or two out of 10 investments are successful. Thus, the success rate $(P)$ varies between $10 \%$ and $20 \%$.

On the left side of Equation 1, there are capital (cash inflow), expectation returns ( $r$ ) and time $(T)$ of the fund. On the right side, is shown the probability of the startup firm to be successful and the income to be earned (cash out).

$$
\text { Cash Int }{ }^{*}(1+r)^{\wedge} \mathrm{T} \text { [Expected return of limited partners] }=\mathrm{P} \times \text { Cash Out [Expected result] (1) }
$$


There is a cash-to-cash (c-c) ratio when the amounts of cash are placed on the left side of the equation and the discount rates on the right side (equation 2).

$$
\text { Cash Out / Cash In }==(1+r)^{\wedge} \mathrm{T} / \mathrm{p}(2)
$$

The ratio of cash outflow (earnings) to cash inflow (cost) is 1 plus the time over return is divided by the probability of success. It also shows how much cash should be issued against each deposit.

As an example, there should be a cash-to-cash recycling rate based on investors' expectations and success.

If the return expectation rate of investors is $(r)=0,1,1$ year is expected $(t)$, the probability of success is $0,1(p)$, it is necessary to withdraw cash from the sale of the starting firm of $11 \mathrm{TL}$ against the cash inflow of $1 \mathrm{TL}$. For example, if two years is expected ( $t), 12,1 \mathrm{TL}$ is required. If a 5 -year exit strategy is foreseen, a cash outflow of $16,1 \mathrm{TL}$ is required against the $1 \mathrm{TL}$ set. The main reason for being extremely high, such as $11,12,16$ times, is due to the low probability of success (P). If the success rate $(P)$ is increased by $20 \%$, the cash to cash rates required in the same example are reduced to 5,5, 6, and 8 times, respectively.

In this case, the area that can be in the price negotiation with the fund, which must meet the expectations of the investors, is narrow. The venture capital fund is not an exit. The startup founders should ask only a sufficient amount of capital. 


\section{Giriş: Girişimciliğin Finansmanı}

Startup potansiyel ekonomik kazanç taşıyan fırsatla başlar. Girişimcinin fırsatı değerlendirebilmesi için destekleyici kaynaklara (finansman, yönetim) sahip olmalıdır. Banka kredileri düzenli nakit akışları gerektirmekte; bu nedenle startuplar borç finansmanına erişememektedirler (Festel, Wuermseher \& Cattaneo, 2013). Ayrıca bankalar kredi karşılığında ipotek talep etmektedirler. Illk finansmanda girişimcinin, kendisi, arkadaşları ve akrabaları önemli rol oynamaktalar. Başlangıç safhası atlatıldıktan sonra, sermaye ihtiyacını karşılamada girişimcinin etrafındaki tanıdıkları yetersiz kalmaktadır. Bu nedenle, startup kurucuları öz kaynaklarının bir kısmını yatırım getirisi bekleyen diğer yatırımcılara satarlar. Bu yatırımcılara risk sermayesi denir. Buradaki en önemli açmaz ne kadar yatırıma ne kadar hisse oranı verileceği yönündedir (Cumming ve Dai, 2011; Gompers, Kovner, Lerner \& Scharfstein, 2010). Bunun bir metodolojisi var mı? Matematiği nasıl işlemektedir? Bu veriler ışığında, startup kurucularının izlemesi gereken stratejiler neler olabilir?

Genellikle startup girişimcisi çok az sermaye karşılığında çok fazla hisse vermiş gibi bir hayal kırıklığı yaşamaktadır. Bazen de teklifi ret etmektedirler. Bu makalede girişimcinin karşı tarafındaki risk sermayesinin organizasyon ve finansal yapıları işlenmektedir. Bu az sermayenin arkasındakinin risk sermayesini göstererek bu oranların bir pazarlık konusu veya bir sömürüden çok sektörün kurgusunun neticesi olduğunun anlaşılmasıdır. Startup'ın izlemesi gereken strateji gösterilmektedir.

Her iki taraf için de yüksek belirsizlik nedeniyle yeni kurulan startuplar'ın gerçek değerini belirlemek zordur (Hochberg, Ljungqvist \& Lu, 2010). Genellikle, startup ne kadar gençse, tarihsel verileri eksikse ve gelecekteki performansı etkileyen birçok yüksek belirsizlik varsa şirkete değer biçmek zorlaşır (Moyen, Slade \& Uppal, 1996; Vinturella ve Erickson, 2004; Berkus, 2016).

Ayrıca risk sermayesini sadece sermaye desteği olarak görmemek gerekmektedir. Risk sermayedarları bağlantılarından faydalandırarak startuplar'a avantajlar sunmaktadırlar. Anahtar müşterileri veya tedarikçileri tanıştırmaktadırlar. 


\section{Risk Sermayesinin Karşılaştıkları Sorunlar ve Önlemleri}

Risk sermayesinin karşılaştığı sorunlardan bazıları: bilgi asimetrisi, belirsizlik, likidite ve risk getirisi (Hsu, 2004, 2007; Engel ve Keilbach, 2007).

Bilgi asimetrisinde, hissedar olarak risk sermayedarları startuplara oranla piyasayı ve kurucuları daha az tanımaktadırlar (Ledyard, 2008; Lerner, 1994).

Bir girişimin ürününe piyasa talebi, maliyet yapıları, pazar kanalları ve takımı gibi pek çok unsur belirsizdir. Startuplarla ilgili sorun, iş modelinin kanıtlanmamış olmasıdır. (Blank, 2013).

Risk sermayedarlarının yatırımı likit değildir. Çıkış yapabilmeleri için startupın halka arzı veya başka bir firmaya satışı gereklidir. Bu da 4 ila 7 yıl sürmektedir (Chiampou ve Kallett, 1989; Sahlman, 1990).

Risk-getiri tarafında, bir risk sermayedarı portföyü çeşitlendirme fırsatı sınırlıdır, özellikle startuplara özgü riskleri ortadan kaldıramaz. Yatırımın risk getirisi hisse senetlerinden farklıdır (Ruhnka ve Young, 1991; Weidig ve Mathonet, 2004; Cochrane, 2005). Cochrane (2005) risk sermayesinde ortalama geri dönüşünün \% 15 olduğunu ve standart sapmanın \% 89 olduğunu bulmuştur. Buda ortalama getiriyi \%100'lere vardıracağı gibieksi getiriden dolayı sermayenin kaybının da olabileceğini öngörmektedir.

Risk sermayedarları bu olumsuzluklara karşı birtakım stratejiler geliştirmişlerdir. Risk sermayesi ortaklarının çoğu sadece riskleri bildikleri endüstrilere yatırım yapmaktadırlar (Kovner, Brewer, Greene \& Fairchild, 2009). Risk sermayesinin uzmanlaşmasının getiriyi yükselttiği gözlenmiştir (Gompers, 1999; Kovner ve ark., 2009). Endüstri uzmanlığının firmaya özgü riski daha etkin bir şekilde azaltmaya yardımcı olduğu varsayımı ile tutarlıdır. Uzman ortaklar en iyi yatırım fırsatlarını daha iyi bulabilir, değer katabilir ve riski azaltabilirler.

Yatırım yaptıkları firma sayısının çeşitlendirmesi riskin yaymanın bir yoludur (Weidig ve Mathonet, 2004). Genellikle bir risk sermayesi portföyü on ila yirmi 
aktif şirketten oluşur (Weidig ve Mathonet, 2004). Kanniainen ve Keuschnigg (2003), optimal portföyün, gerçekleştirilen yatırım sayısı ile katılım yoğunluğu arasında bir denge olacağını belirtmektedirler. Robinson (1987) 53 risk sermayesiyle yaptığı bir ankette, yüksek belirsizlikle başa çıkmanın portföye üç aşamadaki şirketleri dahil etmek olduğunu bulmuştur: tohum, erken büyüme ve genişleme aşaması (Robinson, 1987).

Lerner (1994) girişim kapitalistlerinin diğer girişim kapitalistleriyle ortak yatırım yaparak riski azalttıklarını tespit etmiştir.

Fried ve Hisrich (1994) girişim kapitalistlerinin yatırıma antlaşmasına kadar 100 gün boyunca startupı, ürünü ve piyasayı tanımak için tam zamanlı çaba harcadıklarını göstermektedirler. Yoğun bir tarama ve değerlendirme süreci risk sermayesine yatırım yapmadan önce önemli miktarda bilgi toplamasına izin vermekte ve bu bilginin yanlışs startup seçim sorununu azaltmaktadır (Lerner, 1995; Fernande, 2007; Amit, Glosten \& Muller, 1990; Maxwell, Jeffrey \& Vesque, 2011).

Bu makalenin incelediği risk sermayesinin koruma yöntemleri ise yatırım şekli ve karşılığında aldığı orandır. Sermaye yatırımından önce borç vererek gerçekleşmesi, zamanla belirsizlikler azaldıkça borçların hisseye dönüştürülmesi izlenen stratejilerden bir tanesidir (Damodaran, 2010). Ayrıca yatırım karşıllı̆ında aldığı hisse miktarını yüksek tutmaya çalışmaktadır. Bir startuptan kazandığı kazanç ile diğer statuplardan kaybettiklerini telafi etme gayretindedir.

\section{Venture Capital Firmalarının Finansmanı}

Risk sermayesinden yatırım talep edildiğinde risk sermayesi tarafında sistemin nasıl işlendiğini bilmesi gereklidir (Goldman, 2008; Villalobos, 2007). Risk sermayesi nasıl oluşturulmaktadır? Hissedarlık nasıl belirlenmektedir?

Risk sermayesi bir girişimci grubun başka kişi ve kurumlardan sermaye temin etmesidir. Risk sermaye girişimcilerine sadece parayı temin ettikleri için sınırlı ortak denir. Sınırlı ortaklar emeklilik fonları, şirketler ve zengin kişiler olmaktadır. 
Genel ortaklar risk sermayesi içinde çalışanlardan oluşmaktadırlar. Genel ortaklar yatırım kararlarını verenlerdir. Hangi şirketlere yatırım yapacaklarını belirlerler. Sınırlı ortaklardan veya kendi kaynaklarından gelen sermayeyi kullanırlar. Bu sözleşme genellikle 10 yıllık olmaktadır. Bu süre 3 bölüme ayrılabilir. Yeni yatırım ilk dönemde yapılmaktadır. İkinci dönemde az da olsa yeni yatırım veya mevcut yatırımlara ek yatırımlar ve üçüncü dönemde satış gerçekleşmektedir.

Ortalama olarak 10 ila 15 yatırım yapılmaktadır. Birçoğu başarısızlığa uğramaktadır.

Ortaklık antlaşması, sınırlı genel ortakların nasıl ödeme alacaklarını belirlemektedir. Sınırlı ortaklara ödeme iki şekilde olmaktadır. Birincisi, işletme ücreti olarak sektördeki oran \%2 ile 2,5 arasındadır. Öyleyse 200 milyon TL'lik bir fonun yönetim ücreti 4 milyon TL olmaktadır.

İkincisi, sınırlı ortakların startup çıkışlarından oluşacak kardan alacakları primdir. Sektörde genel kural \%20 oran olarak belirlenmiştir. Örneğin 200 milyon TL yatırım 10 yıl sonra 400 milyon TL olmuşsa. 200 milyonluk karın \%20 si olan 40 milyon TL'yi genel ortaklar kazanırlar.

Burada önemli nokta sınırlı ortakların başkalarının paralarını kullanıyor olmalarıdır. Genel ortakların prim alabilmeleri için sınırlı ortakların beklentilerinin karşılanmasıdır.

Şekil 1. Risk sermayesi yapısı

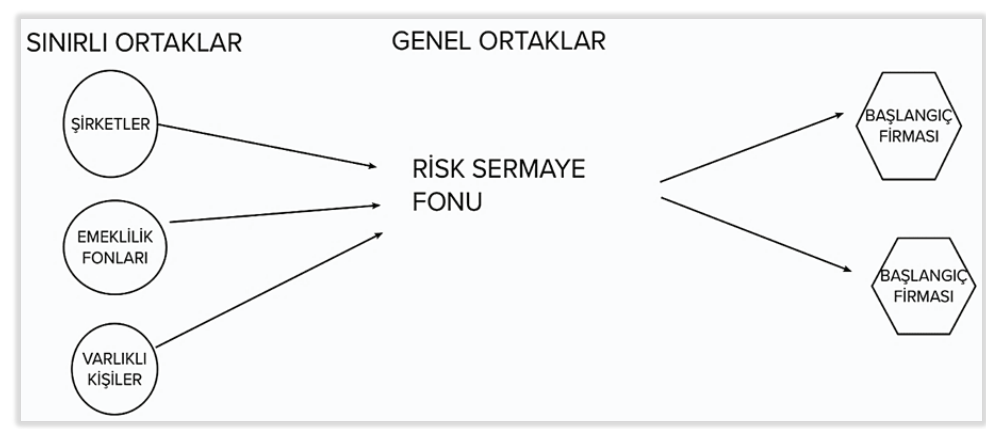

Kaynak: Bilgiler yazar tarafından derlenerek hazırlanmıştır 


\section{Değerlendirme Öncesi ve Sonrası}

Değerlendirme sonrası risk sermaye yatırımcısının başlangıç firması yatırımı sonrası belirlenen değerdir. Örneğin bir startup \%5'lik hisse karşılığında 20 milyon TL yatırım aldığında, firmanın değeri 400 milyon TL'dir. Bu rakama değerleme sonrası (post valuation) olarak adlandırılır. Değerlendirme öncesi değeri 380 milyon TL'dir (400 milyon TL'den 20 milyon TL'yi çıkartılarak bulunur).

\section{VC Koruma Mekanizması: Değiştirilebilir Tercihli Hisse}

Risk sermaye firması başlangıç firmasının riskinden dolayı hisse senedine dönüştürülebilir borç vermeyi tercih edebilir. Buna değiştirilebilir tercihli hisseler (convertible share) denmektedir. Hisse alımıyla borç enstrümanının karışımıdır.

Risk sermayesi başlangıçta yatırım yaptığında girişimlerdeki yüksek riskten dolayı özel haklar almaktadır. Değiştirilebilir hisse senetleri borç verilmesi gibi faiz geliri alır. Bu faiz ödemeleri girişim firmasındaki eksi nakit akışından ötürü genellikle birikir. Sözleşmede öngörülen zaman geldiğinde risk sermayesi ya borç olarak tutar ya da borcu faiziyle beraber hisseye dönüştürür. İleri ki bir zamanda hisse senedine dönüştürme hakkı risk sermayedarı için bir korumadır. Çünkü zamanla işin gidişatı daha iyi anlaşılıp, ortaklığa girebilme opsiyonu taşımaktadır.

Örneğin, bir firmanın 100 adet hissesi var. 80 tanesi standart hisse ve 20 tanesi değiştirilebilir hisse senedi. Sözleşmeye göre 1 değiştirilebilir hisse senedi 1,8 adet standart hisseye dönüştürülebilir ve hisse payının $10 \mathrm{TL}$ nominal değeri var. Bu durumda borç miktarı 200 TL'dir (20 hisse çarpı $10 \mathrm{TL}$ ). 20 tanesi dönüştürme tercihi kullanıldığında, 36 adet olmakta ve toplam hisse adeti 116'ya çıkmaktadır. Bu durumda 36'nın 116'ya bölümü \%31'e denk gelmektedir. 20 tane değiştirilebilir hisse senedi şirkette \%31'lik pay alma opsiyonu vardır.

Hangi durumda borç verir veya hissedar sahibi olmayı yeğler? Buradaki kritik nokta girişimin değeridir. 
Eğer firmanın değeri 200 TL'nin altında kalırsa, VC iki opsiyonundan alacaklı kalmayı tercih edecektir. Çünkü 200 TL karşılığında \%31'ine sahip olmaktansa, 200 TL'nin tamamına elde etmek daha karlıdır. \%31'ine karşılık gelen startup değerinin 200 TL'yi geçmesi gereklidir. Bu değiştirilebilir tercihli hisse durum risk sermayesini zarara karşı korurken, startup kurucularının da yüksek değerlendirme çıtasına ulaşmaya zorlamaktadır. Girişimcilerin kar edebilmeleri için 200 TL'nin çok üstünde bir rakama çıkmaları gerekmektedir.

\section{Risk Sermayesi Girişim Firmasını Nasıl Değerlendirir}

Bu bölümde risk sermayesinin yatırım yaptıkları işi nasıl değerlendirdiği gösterilmektedir (Bulut ve Er, 2010). Risk sermayesi pahalı bir finansal araçtır. Risk sermayedarlarının kullandıkları indirgeme oranı standart proje değerlendirme indirgeme oranlarına göre çok daha yüksektir. Özellikle bu indirgeme oranının etkisini yatırıma karşı talep ettiği yüksek pay sahipliğinde görülmektedir.

İndirgeme oranın arkasında iki ana faktör vardır: risk sermaye firmalarının kurgusu ve girişimlerin riski. Risk sermayesi başkalarının paralarını uzun bir süre için kullanmaktadır. Sınırlı ortakları bu bekleme süresini katarak bir getiri beklemektedir.

Risk sermayesinin yaptıkları yatırımların bir bölümü başarısız olmaktadır. Sektör ortalaması 10 yatırımdan bir veya ikisinin başarılı olduğu yönündedir. Buradan hareketle başarı oranı (P) \%10 ile \%20 arasında değişmektedir.

Denklem 1'in sol tarafında sınırlı ortakların koydukları sermaye (nakit girişi), beklenti getirileri $(r)$ ve fonun zaman $(T)$ süresi vardır. Sağ tarafında ise başlangıç firmasının başarılı olma ihtimali ve kazanılacak geliri (nakit çıkısı) göstermektedir.

Nakit Girişi ${ }^{*}(1+r)^{\wedge} \mathrm{T}[$ SInırlı ortakların getiri beklentisi $]=\mathrm{P} \times$ Nakit Çıkışı [Beklenen sonuç] (1)

Nakitleri denklemin sol tarafında ve indirgeme oranlarını sağ tarafına konduğunda nakite-nakit (c-c) oranı bulunmaktadır (denklem 2) (Bulut ve Er, 2010). 
Nakit Çıkışı /Nakit Girişi $=(1+r)^{\wedge} T / p(2)$

Nakit çıkışın (kazancın) nakit girişe (maliyetin) oranı 1 artı getiri üstü zamanın başarılı olma ihtimaline bölünmesidir. Aynı zamanda her konan nakite karşı ne kadar nakit çıkışı olması gerektiğini göstermektedir.

Nakite nakit oranı ne olmalıdır? Sınırlı ortakların beklenti getirisiyle startupların başarılı olma ihtimaline bağlıdır.

Bir örnekle yatırımcıların beklenti ve başarı ihtimaline göre nakitten nakite geri dönüşüm oranı bulunsun.

Yatırımcıların getiri beklenti oranı $(r)=0,1,1$ yıl beklense $(t)$, başarı ihtimalide 0,1 (p) olsa 1 TL'lik nakit girişine karşı 11 TL'lik başlangıç firmasının satışından nakit çıkış gereklidir. Örneğin 2 yıl beklense (t), 12,1 TL gereklidir. Eğer 5 yıllık bir çıkış stratejisi ön görülüyorsa, koyulan 1 TL'ye karşı 16,1 TL'lik nakit çıkış gereklidir. 11, 12 ve 16 kat gibi aşırı yüksek olmasının ana sebebi başarı ihtimalinin düşüklüğünden ileri gelmektedir (P). Eğer başarı oranı (P) \%20 yükselse, aynı örnekte gereken nakite nakit oranları sırasıyla 5,5 ile 6 ve 8 kata inmektedir. Risk sermayesinin başarılı bir girişimden alınacak hisse miktarı diğer tüm başarısız girişimlere yatırılacak parayı telafi etmesi gerekmektedir. Bu oranlar göstermektedir ki, konan nakite karşı çok yüksek bir nakit çıkışı olmalıdır.

Sınırlı partnerlerin istedikleri getiri oranını yakalamak için, nakite nakitte istenen geri dönüşümü bir yatırım projesinin değerlendirilmesinde kabul edilebilir en düşük getiri oranı (hurdle oranı) dönüştürülebilir. Bu oranı bulmak için getiri oranı T (zaman) kökü alınıp 1'den çıkartılmaktadır (denklem 3).

Kabul edilebilir en düşük getiri oran $=\sqrt[t]{\frac{\text { Nakit Çıkışı }}{\text { Nakit Girişi }}}-1=\sqrt[t]{\frac{(1+r)^{\wedge} T}{P}-1}$

Kabul edilebilir en düşük oranında risk sermayesinin başlangıç firmasından alması gereken hisse oranı (miktarını) belirlemektedir. Başlangıç firmalarında riskler 
büyüdükçe kabul edilebilir en düşük oranda yükselmektedir. Yatırım zaman uzunluğu riski büyütür.

Bir örnekle, kabul edilebilir en düşük risk oranı bulunsun. Bir startup firmasına yapılacak yatıım 100 TL olsa ve startup'ın beklenen çıkış fiyatı 20.000 TL olsa, 5 yıl bekleme süresi, \%10 başarı ihtimali ve \%15 getiri beklentisi elde edebilmek için başlangıç firmasından talep edilecek kabul edilebilir en düşük getiri ve nakite nakit oranları nedir?

Nakitte nakit oranı için denklem 2 kullanılmaktadır. $(1+0,15)^{\wedge} 5 / 0,1$ durumunda 20 'dir. Kabul edilebilir en düşük getiri oranı ise denklem 3 kullanılarak bulunacak oran \%82'dir. Bu durumda sınırlı ortak yatıımcıların 5 yıl boyunca, \%15'lik getiri beklentisini karşılayabilmek için \%10'luk başarı ihtimaline karşılık, \%82 indirgeme oranı kullanmak gereklidir. Kabul edilebilir en düşük getiri oranı standart finansal yatırımlara (mearkuat, tahvil ve hatta hisse senedi) göre çok daha yüksektir. 20.000 TL beklenen çıkısıı şimdiki değerini bulmak için (net present value), çıkıs değeri nakite nakite veya $1+$ indirgeme oranı üstü zamana bölünmektedir: 20000/20 veya 20.000/(1+0,82)^5), 10000 TL'dir (Robinson, 2020).

Bu durumda 100 TL'lik yatırıma karşı ne kadarlık hisse alınması gerektiğini göstermektedir: 100/1000: \%10.

Girişimci büyük bir para kazanacağını düşünerek (20.000 TL) ve risk sermayedarından sadece 100 TL'lik finansal yatırım isterken ve çok az bir karşllık vereceğini umarken, \%10'luk hisse talebiyle şaşırtmaktadır. Ancak arka plandaki risk sermayesinin kurgusundan dolayı organizasyonel, matematiksel ve istatiksel olarak talep edilmesi gereken hisse miktarı budur. Burada risk sermayedarının savunması girişimcinin başarısının garanti olmadığıdır.

\section{Yeni Örnekler}

Denklemleri kullanarak yukardaki örneklerden ihtimali, getiri ve beklenen zaman sürelerini değiştirerek farklı örnekler çözülmektedir. 
Illk örnekte şirketin beklenen karından hareket edilsin. Faiz ve amortisman öncesi (FAVÖK) karı 100 milyon TL olacağı ve 6 katına satılacağı düşünülen bir başlangıç firmasına 10 milyon TL konduğunda yatırımcının talep etmesi gereken hisse oranı nedir?

Getiri beklentisinin \%18 olduğunda, 5 yıl bekleme durumunda nakite nakite oranı 11,4 kat olmaktadır (denklem 2). Firmanın çıkış satışının 600 milyon TL (6 çarpı 100 milyon) olduğunda şimdiki değeri 52 milyon TL'dir (600/11,4). 10 milyon TL konduğunda \%19 hisse almalıdır.

Yeni örnekte gereken çıkış fiyatı hesaplansın. Risk sermayedarlarının yatııımcılarının getiri beklentisi \%20, fonun 7 yıl bekleme süresi ve başarı ihtimalide \%10'dur. 15 milyon TL'lik \%30'a karşı gelen hisse alan yatırımcının çıkış fiyatı ne olmalıdır?

Bu durumda nakite nakit oranı 35,8'dir $\left.\left((1+0,2)^{\wedge} 7\right) / 0,1\right) .15$ milyona karşı \%30 alınmışsa, şimdiki değeri 45 milyon TL'dir. 45 milyonu 35,8 nakite nakit ile çarpıldığında, 1,7 milyar TL eder. Fonun bekleme süresi ve getiri beklentisi yükseldiğinde gereken çıkış fiyatı da astronomik şekilde artmaktadır.

\section{Sulanma Durumunda}

Startuplar ilk finans turunda aldıkları yatırımdan sonra ilerde doğacak finansal ihtiyaçlar için yeni turlar düzenlemeleri gerekebilir. Eğer önceki turlara katılan risk sermayedarları yeni tura katılmazlarsa, hisseleri sulanır (dilute). Eğer bu sulanmayı öngörüyorsa, cari sahiplik miktarını ayarlar.

Sulandırma etkisini göz önünde bulundurulduğunda cari sahiplik oranı denklemi şöyledir (Scherlis ve Shalman, 1989):

Gerekli Cari Sahiplik Yüzdesi= Gerekli Nihai Sahiplik Yüzdesi/ Sulanma Oranı (Denklem 4) 
Bu denklemin açıımına göre yukardaki örneklerden birine uygulandığında talep edilecek hissedarlık oranındaki değişme gözlemlenebilir. Illk örneğe sulanma oranına eklenmesi italikle gösterilmektedir.

Bir startup firmasına yapılacak yatırım 100 TL olsa ve startup'ın beklenen çıkış fiyatı 20.000 TL olsa, 5 yıl bekleme süresi, $\% 10$ başarı ihtimali, \%15 getiri beklentisi ve \%50 sulanacağını tahmin etse, elde edebilmek için başlangıç firmasından talep edilecek kabul edilebilir en düşük getiri ve nakite nakit oranları nedir?

Burada aynı çözüm metoduyla ilerledikten sonra \%10 oranı, \%50'ye bölünmektedir (denklem 4). Talep edilecek miktar \%20 yükselmektedir. Çünkü risk sermaye firması çıkış sonucunda alması gereken nakit çıkışı miktarına göre hisse oranını ayarlamaktadır.

\section{Sonuç ve Tartışma}

Startuplar sürekli büyüme gösterdiklerinden dolayı süreç içinde dışarıdan yatırıma ihtiyaç duyacaktır. Burada risk sermayedarlarıyla izlenmesi gereken strateji doğru miktarda parayı doğru zamanda talep etmektir. Doğru zaman şirketin bir çıkış değeri ortaya çıkması, büyümesini finanse edilecek olması. Doğru miktar kendisini ayakta tutacak miktardır. Risk sermaye yatırımı bir çıkış ödemesi değil maliyeti yüksek bir yatırımdır. Gereksiz harcamalardan tamamen kaçınmalıdır. Ne kadar az yatırım alırsa, karşılığında o kadar az hisse vermesi gerekmektedir.

\%15 getiri beklentisi olan yatırımcının, startup'ın \%20 başarı ihtimali ve 7 yıl bekleme süresi için koyulacak 1 milyon TL'ye karşı 13 milyon TL'lik nakit çıkısıı talep edecektir. Eğer firmanın çıkış satış fiyatı 26 milyon TL olursa, bu durumda risk sermayesi 1 milyon TL'lik yatıııma karşı alması gereken 13 milyon TL'lik pay \%50 hissedir. 26 milyona satılacak firma için girişimci firmanın yarısından vazgeçmelidir. $\mathrm{Bu}$ durumda yatırımcıların beklentisini karşılamak zorunda olan fonla fiyat pazarlığında oynanabilecek alan dardır. Burada talep edilen miktarın azaltılması ve tekrar ihtiyaç olduğunda yeniden sermaye desteği beklenebilir. 
Bu kadar yüksek fırsat maliyetinin olmasının sebebi startupların tarihsel verilerinin eksikliği ve geleceğe dair birçok belirsiz faktörün göz önüne alınmasıdır.

Belirsiz kazançlar, geçmişi olmaması ve benzer şirketlerin az olmasına başarı ihtimalini düşürmektedir. Risk sermayesinin yatırımcılarının zaman ve beklenti getirileri vardır.

Risk sermayesi değerlemelerini gelecekteki nakit akışının indirgeme oranı yaklaşımıyla yapmaktadır. Startuplar'daki başarısızlık riskinin yüksek olduğunu hesaplanarak, standart oranının çok misliyle indirgeme oranı kullanmaktadır. Çıkış fiyatı nakite nakit oranına bölündüğünde net şimdiki değeri (NPV) vermektedir.

Hakem Değerlendirmesi: Dış bağımsız.

Çıkar Çatışması: Yazar çıkar çatışması bildirmemiştir.

Finansal Destek: Yazar bu çalışma için finansal destek almadığını beyan etmiştir.

Peer-review: Externally peer-reviewed.

Conflict of Interest: The author has no conflict of interest to declare.

Grant Support: The author declared that this study has received no financial support.

\section{Kaynakça/References}

Amit, R., L. Glosten \& Muller, E. (1990). Entrepreneurial ability, venture investments, and risk sharing. Management Science, October, 1232-1245.

Berkus, D. (2016). After 20 years: Updating the Berkus method of valuation, Retrieved: May 11, 2017, from https://www.angelcapitalassociation.org/blog/after-20-years-updating-the-berkusmethod-of-valuation/

Blank, S. (2013). Why the lean start-up changes everything. Harvard Business Review, 4(2), 34-40.

Bulut, H, Er, B. (2010). Risk sermayesi destekli girişimlerin fiyatlandırılması ve fiyatlandırmada kullanılan ıskonto oranı, Atatürk Üniversitesi Sosyal Bilimler Enstitüsü Dergisi, 11(1), 275-297.

Chiampou, G. E. \& Kallett, J. L. (1989), Risk/return profile of venture capital. Journal of Business Venturing, 4(1), 1-10.

Cochrane, J. (2005). Financial markets and the real economy. NBER Working Papers, 11193.

Cumming, D. \& Dai, N. (2011). Fund size, limited attention and valuation of venture capital backed firms. Journal of Empirical Finance, 18, 2-15. 
Damodaran, A. (2010). The dark side of valuation: Valuing young, distressed, and complex businesses. New Jersey: Pearson Education.

Engel, D. \& Keilbach, M. (2007). Firm-level Implications of Early Stage Venture Capital Investment: An Empirical Investigation. Journal of Empirical Finance, 14, 150-167.

Fernande, P. (2007). Company valuation methods. The most common errors in valuations. IESE Working Paper No. 449, Navarra.

Festel, G. Wuermseher, M. \& Cattaneo. G. (2013). Aluation of early stage high-tech start-up companies. International Journal of Business, 18(3), 216-231.

Fried, V. H. ve Hisrich, R. D. (1994). Towards a model of venture capital investment decision making. Financial Management, Autumn, 28-37.

Goldman, M. (2008). Valuation of startup and early-stage Companies. The Value Examiner. July-August.

Gompers, P. (1999). A note on valuation in entrepreneurial ventures. Harvard Business School, Case 9298082, 1-17.

Gompers, P., Kovner, A., Lerner, J. \& Scharfstein, D. (2010). Performance persistence in entrepreneurship, Journal of Financial Economics, 96, 18-32.

Hochberg, Y. V., Ljungqvist, A. \& Lu, Y. (2010). Networking as A barrier to entry and the competitive supply of venture capital. Journal of Finance, 65, 829-859.

Hsu, D. H. (2004). What do entrepreneurs pay for venture capital affiliation? Journal of Finance, 59, 1805-1844.

Hsu, D. H. (2007). Experienced entrepreneurial founders, organizational capital, and venture capital funding. Research Policy, 36, 722-741.

Kanniainen, V. \& Keuschnigg, C. (2003). The optimal portfolio of start-up firms in venture capital finance. Journal of Corporate Finance, 9(5), 521-534.

Kovner, C. T., Brewer, C. S., Greene, W. \& Fairchild, S. (2009). Understanding new registered nurses' intent to stay at their jobs. Nursing Economics, 27(2), 81Y98.

Ledyard, J. (2008), Market Failure in Durlauf, S. and L Blume (eds). The New Pal-grave Dictionary of Economics, $2^{\text {nd }}$ ed. Baasingstroke: Macmillan.

Lerner, J. (1994). The syndication of venture capital investments. Financial Management, Autumn, 16-27.

Lerner,J. (1995). Venture capitalists and the oversight of private firms. Journal of Finance Literature, 301-318.

Maxwell, A. L. Jeffrey, S. A. and Vesque, M. L (2011). Business angel early stage decision making. Journal of Business Venturing. 26, 212-225.

Moyen, N., Slade, M. E. \& Uppal, R. (1996). Valuing risk and flexibility - a comparison of methods. Resources Policy, 22, 63-74.

Robinson, D. (2020). How VCs Value Businesses? in Startup Valuation Methods Course with Manuel Adelino, Duke University. Erişim adresi: https://www.coursera.org/lecture/startup-valuationmethods/how-vcs-value-businesses-Nq18X

Robinson, R. (1987). Emerging strategies in the venture capital industry. Journal of Business Venturing, $2,1,53-77$. 
Ruhnka J. C. \& Young, J. E. (1991). Some hypotheses about risk in venture capital investing. Journal of Business Venturing, 6(2), 115-133.

Sahlman, W. A. (1990). The structure and governance of venture capital organizations. Journal of Financial Economics, 27, 473-521.

Scherlis, D. \& William, S. (1989). A method for valuing high-risk, longterm investments. Harward Business School, Note: 9-288-006, pp: 1-54.

Villalobos, L. (2007). Investment valuations of seed-and early-stage ventures. eVenturing.

Vinturella, J. B. \& Erickson, S. M. (2004). Raising entrepreneurial capital. Academic Press, Waltham.

Weidig, T. \& Mathonet, P. (2004). The risk profile of private equity. SSRN, 495482. 
